\title{
Chapter 11 \\ Development of a New Mathematical \\ Framework for Seismic Probabilistic Risk \\ Assessment for Nuclear Power Plants - Plan and Current Status -
}

\author{
Hitoshi Muta, Ken Muramatsu, Osamu Furuya, Tomoaki Uchiyama, \\ Akemi Nishida, and Tsuyoshi Takada
}

\begin{abstract}
After the severe accident in Fukushima Daiichi Nuclear Power Station, safety improvement and enhancement have been installed. In midterm and long term, continuous efforts to improve and enhance safety are required, and technical basis and fundamentals are needed to achieve them.

Probabilistic Risk Assessment for seismic event (seismic PRA) is an effective measure to consider the countermeasures and improvement plans to secure the further safety of nuclear power plants regarding to seismic risk for the earthquake exceeding the design basis earthquake ground motion. However, the application of seismic PRA has not been utilized sufficiently so far. One of the reasons is that there is not enough agreement among stakeholders regarding to the evaluation methodology and consideration of uncertainty for decision-making.

This study proposes the mathematic framework to treat the uncertainty properly related to the evaluation of core damage frequency (CDF) induced by earthquake, the methodology to evaluate the fragility utilizing expert knowledge, the probabilistic model to cope with the aleatory uncertainty as well as the development of analysing code including these considerations for the improvement of the reliability of the methodology and enhancement of utilization of the products of seismic PRA.

This paper presents current status and some results from scoping calculations.
\end{abstract}

H. Muta $(\bowtie) \cdot$ K. Muramatsu • O. Furuya

Department of Nuclear Safety Engineering, Tokyo City University, Setagaya-ku, Tokyo, Japan e-mail: hmuta@tcu.ac.jp

T. Uchiyama

CSA of Japan, Minato-ku, Tokyo, Japan

A. Nishida

Center for Computational Science and e-Systems, Japan Atomic Energy Agency, Naka-gun, Ibaraki, Japan

T. Takada

Department of Architecture, The University of Tokyo, Bunkyo-ku, Tokyo, Japan

K. Kamae (ed.), Earthquakes, Tsunamis and Nuclear Risks,

DOI 10.1007/978-4-431-55822-4_11 
Keywords seismic PRA - Mathematical Framework - Uncertainty Analysis • High-Performance Computing • SECOM2-DQFM

\subsection{Background}

After the Fukushima Daiichi accident, safety enhancement of nuclear power plants in Japan is required by the new regulation. Moreover, continuous efforts to improve the reinforcement of risk management will be required in the middle or long term, and technical basis will be needed to support it. The importance of seismic PRA as a tool to identify potential accident scenarios caused by earthquakes, to estimate their likelihood and consequences and to support in assessing the effectiveness of measures to enhance safety against earthquakes has been widely and strongly recognized. However, seismic PRA has not been applied enough to achieve the aim above. One of the reasons is that there has been sufficient discussion and consensus building about the quantification and reduction of uncertainties in numerical results of seismic PRA and how to consider the uncertainty for decision-making.

In this study, a new mathematical framework of seismic PRA is proposed. Reviewing the current status of assessment procedures of accident sequence analysis in seismic PRA, this study will develop a new mathematical framework for estimating uncertainty in SPRA results in a more comprehensive way, taking into account uncertainties related to correlation effect of components failures which has been difficult to quantify so far. A computer code will be developed to materialize the proposed framework on the basis of the SECOM2-DQFM developed by JAEA to estimate the accident sequence occurrence probability and its uncertainty. The proposed mathematical framework is characterized by the following points:

- Representation of seismic hazard by a set of time histories of seismic motions using methods currently being developed by Nishida et al.

- Use of probabilistic response analysis by three-dimensional building model for determining responses of components to the seismic motions including the correlations among the component responses

- Use of Monte Carlo simulation for quantification of fault trees in accident sequence analysis

- Use of high-performance computing technology for realizing the use of above technologies in seismic PRA

Current status and some results from scoping calculations will be presented. 


\subsection{Current Framework and Challenges of Seismic PRA Methodology}

In this chapter, firstly, general procedure and mathematical framework current method of seismic PRA should be reviewed; then issues of current uncertainty analysis framework will be extracted. Moreover, previous studies possibly to resolve the issues of mathematical framework.

\subsubsection{Current Method of Seismic PRA}

\subsubsection{General Procedure of Seismic PRA}

This study focuses the method of level 1 seismic PRA that evaluates the frequency of core damage accident. In general, the basic procedures of level 1 seismic PRA are shown in Fig. 11.1 and can be characterized as followings:

(a) Collecting the plant information and analyzing brief accident scenarios

To investigate the seismic source around the target site, characteristics of soil and structures, and safety system configuration, the brief accident scenarios induced by earthquakes are extracted.

(b) Seismic hazard analysis

Based on the information about faults around the target site and historical earthquake, occurrence frequencies of seismic ground motion exceeding a certain capacity such as maximum ground acceleration.

(c) Fragility analysis

To analyze the response and capacity of structures and components, the failure probabilities of structures and components can be expressed as fragilities, i.e. the function of capacity of seismic ground motion.

(d) Accident sequence analysis

To analyze seismic induced core damage accident sequences using event-tree (ET) and fault-tree (FT) techniques, core damage frequencies are evaluated based on these accident sequences, results of hazard analysis and fragility analysis.

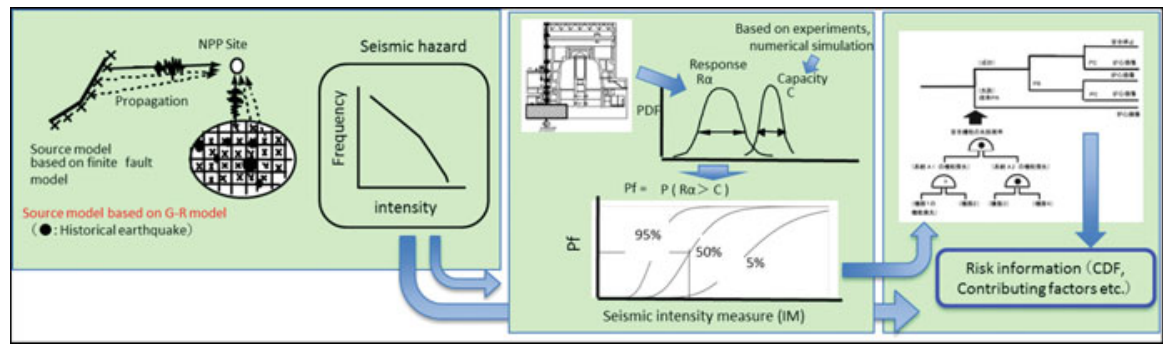

Fig. 11.1 Outline of seismic PRA methodology 


\subsubsection{Mathematical Framework of Current Method}

In this study, focusing on the above items (c) and (d), mathematical model considering uncertainties of components and system failures will be studied. The mathematical framework for evaluating frequencies of accident sequences of seismic PRA is based on the concept by Kennedy et al. [1] and characterized as follows:

- The results of hazard analysis will be expressed as exceeding probabilities, that is, occurrence frequencies of seismic ground motions depending on the capacity on the target site. The levels of seismic ground motions are expressed as maximum accelerations of the surface.

- The wave used for response analysis is one of the time histories of waves such as design basis seismic ground motion. The impacts of variability of ground motion spectra are considered as variability of response factors explained later.

- The fragilities of components can be expressed as the probability that response exceeds capacity of the components, based on the assumption that probability distributions of response and capacity depending on the levels of seismic ground motion are the log-normal distribution, respectively.

- The median values of response depending on the seismic level are evaluated by linear extrapolation for the component response results associated with design basis seismic motion or interpolation of the results of calculations performed at several levels of ground motion.

- Standard deviations on the log scale for the response can be evaluated by expert opinion based on the results of the similar response analysis or comparison among observation points. Usually, response can be analyzed by the Swayrocking model.

- Since responses are usually analyzed based on the design basis framework, response factors are introduced to consider impacts included in the assumption to secure conservatives of the design and to describe impacts of the uncertainty of model or data.

- Component capacities are expressed by median value and standard deviation; these parameters are set based on the results of structural analysis or verification test and, if necessary, expert opinion.

- Occurrence conditions of accident sequences are expressed as groups of minimal cut sets (MCS) equivalent to logical expression of accident conditions expressed by ET and FT. To calculate occurrence probabilities of these MCSs, the probability of certain accident sequence can be evaluated associated with the certain level of seismic ground motion.

- Core damage frequencies can be evaluated by the integration of the product of the probability of accident sequence associated with the certain ground motion level and seismic frequencies all over seismic ground motion levels.

Since the most important characteristics of the current framework is the extensive use of design information and the safety factors (response factors and capacity factors) that express the conservatism in the models used response and capacity evaluations in design, the current methodology is frequently called "the factors of safety method". 
On the other hand, the method of Seismic Safety Margins Research Program (SSMRP) [2] is the other mathematical framework which adopts more detail model and input than that by Kennedy et al.; however, SSMRP method has not been fully used because of its complexity. Based on SSMRP method, new mathematical framework of this study will be established and presented in the next chapter.

\subsubsection{Studies About Uncertainty Analysis Framework}

\subsubsection{Uncertainty Analysis Framework of Current Method}

Current method was proposed to evaluate component failure probabilities by Kennedy et al. in 1980. The characteristics are as follows:

- Uncertainty of seismic hazard is expressed by the fractile curves that are composed of multiple curves corresponding to the percentage of the confidence level or aggregate curves corresponding to each set of alternative models and assumptions in calculating the hazard curve.

- Main causes of variability of model and data expressing response and capacity are categorized to "aleatory uncertainty" (or "uncertainty due to randomness") and "epistemic uncertainty" (or "uncertainty due to lack of knowledge"). The first one can't be reduced by the insights of experiments or theoretical studies because this type of variability is caused by inherent randomness of natural phenomena. The second one can be reduced by the insights of expansion of experimental data and enhancement of analysis models because this variability comes from lack of knowledge or simplification of analysis model.

- Usually, uncertainties in hazard analysis, fragility analysis, and in parameters of accident sequence models are propagated to the uncertainty in core damage frequency, while uncertainty of event tree and fault trees used in accident sequence analysis are considered by sensitivity studies.

\subsubsection{Issues of Current Mathematical Framework}

Seismic PRA is expected to provide useful insights and information for various decision-making. Important uses include the quantitative evaluation of the safety level of NPPs by comparing core damage frequency with quantitative safety goals and extraction of important accident sequences in a viewpoint of contribution to the total risk to enhance the safety features and accident countermeasures. So the followings are desirable and these needs are enhanced after Fukushima Daiichi accident:

- To reduce uncertainty in core damage frequency as far as possible.

- Plant damage states should be analyzed in detail. For example, how many systems failed simultaneously, how many structures such as buildings or piping failed or how they failed? What are the impacts of simultaneous occurrence of accidents in different units in a multiple unit site? 
However, current seismic PRA method (the factor of safety method) has several difficulties that hinders improvement of its numerical accuracy; in other words resolution capability, for identifying important contributors, and many of them are tightly related to the simplification in the mathematical framework described above and are shown as follows:

\section{(a) Issues Mainly Related to the Hazard Analysis}

- The characteristic of seismic motion is expressed by only one parameter, i.e. peak ground acceleration. This means that dependency between the characteristic of the seismic source, i.e. distance and magnitude, and component failures is not modelled precisely enough.

(b) Issues Mainly Related to the Fragility Analysis

- Analytical models used in design calculations, for example, one-dimensional wave propagation model for the ground and Swayrocking model for the building, sometimes may not be sufficient to provide detailed information to express the failure modes of structures and components precisely. The importance of the models to account for the threedimensional response characteristics of the reactor building was pointed out after the Chuetsu-Oki earthquake in Japan.

- In such cases, building response models used in design have to be replaced by more detailed models such as three-dimensional finite element (3D-FEM) models. However, the use of such advanced models needs some additional efforts and information. It needs more detailed input seismic motion which should better be calculated from three-dimensional ground model using threedimensional time history seismic motion data. This information is not provided from current framework of seismic hazard analysis. Furthermore, the parameters to express uncertainties in responses (the logarithmic standard deviation of response factors) have to be prepared. For Sway-rocking models, such parameters may be determined from existing studies. Since such preceding studies are not available for advanced models, some uncertainty calculations using the Monte Carlo or other statistical method will be necessary.

Although the required accuracy of response calculations in seismic PRA may not be as high as that required in deterministic safety assessments, it is desirable to have quantitative information on the impact of the differences in response calculations by different approaches.

(c) Issues Mainly Related to the Accident Sequence Analysis

- In case that response factor method is adopted in components response analysis, coefficients of correlation should be evaluated separately to consider the correlation of component response.

- In case that MCSs are used to evaluate core damage frequencies, since quantification considering simultaneous occurrence of multiple MCSs or dependency among multiple MCSs, error of calculation of core damage frequency tends to be increased. 
- Since the range of correlation will be restricted, uncertainty of core damage frequency or contribution of each accident sequences tends to be increased.

- In case that initiating events are expressed by using hierarchical event tree, it is not obvious that the impacts of the simultaneous occurrences of multiple initiating events are considered sufficiently in the analysis. Moreover, since accident scenario analysis is very rough, resolution of the method could be reduced.

\subsubsection{Previous Studies Possibly to Resolve the Issues of Mathematical Framework}

Issues described above are possibly going to be resolved by the several previous studies. Individual insights and achievements to resolve the issues are the following:

\section{(a) Previous Studies Related to Hazard Analysis}

- Studies related to prediction of seismic motion regarding to modelling of seismic source using fault model, Green function method, semiempirical Green function method, and the combination of these methods can provide time historical wave considering seismic source characteristics.

- Nishida et al. proposed the method expressing seismic hazard by multiple time historical waves weighted by frequencies based on these above studies [3].

(b) Previous Studies Related to Fragility Analysis

- 3D response of structures and components evaluated by the techniques of structure response analysis such as finite element method (FEM) is gradually used to confirm the validity of seismic design.

- The enhancement of grid-computing method that makes high speed computing of structural response analysis possible using supercomputers makes large-scale FEM practical.

- Nishida et al. proposed the construction method of large-scale 3D plant model based on the structural analysis method, and it makes gradually possible the response analysis of major components of nuclear power plant using one linked model and the prediction of the failure point by detailed analysis of local stress of components.

- So many studies about probabilistic structural response analysis of components and structures have been done, for example, analysis of primary containment vessel by Takasaka et al. and failure probability analysis of piping system by Whitaker et al. Though preparation of time history wave associated with the level of seismic motion will be needed to link these insights to seismic PRA, however, those kinds of studies have not been done so far.

- For correlation of response of components, generic rule that describes how to evaluate the correlations among many components and to give the 
coefficients of correlation considering the relationship among correlation of component, specific frequency of each component, and specific location in the building based on the probabilistic response analysis of structures was proposed in the SSMRP study. This is applied to the assessment of two nuclear power plants in NUREG-1150. Moreover, JNES, TSO of the former regulation body of Japan, studied to evaluate the correlation of response based on the soil-structure conditions using similar method and disclosed the results. These studies presented that it is possible to evaluate the correlation using probabilistic response analysis and implied that it could be possible to derive the rule to give the correlation coefficient from a series of detailed calculations in the simplified manner.

\section{(c) Previous Studies Related to Accident Sequence Analysis}

- Muramatsu et al. proposed the method that makes many samples of capacity and response by Monte Carlo simulation for quantification of FT in seismic PRA, named DQFM (direct quantification of fault tree using Monte Carlo simulation) [4, 5]. DQFM method is possible to quantify FT accurately better than MCS method and to consider the correlation of response among components in more general way. Moreover, SECOM2-DQFM that includes DQFM method is disclosed.

- DQFM method can calculate core damage frequency precisely even multiple initiating events occur simultaneously. So it could be useful to resolve the issue that accident sequence might be too much simplified by the hierarchical event-tree method if appropriate improvement is installed.

However, since huge efforts will be needed to make the mathematical treatment consistently from hazard analysis to accident sequence analysis to develop the new framework and method and to improve the whole mathematical method thoroughly in the application of insights and achievements of these above studies, current method has not been improved so far.

\subsection{New Mathematical Framework for Seismic PRA Enhanced by High-Performance Computing}

Based on the previous chapter, this study proposes brand new framework to resolve the issues above. This framework should be characterized by the following features:

\section{Seismic Hazard Analysis}

- Seismic hazard can be expressed by set of the groups including a set of seismic waves weighted by the occurrence frequencies based on the studies by Nishida et al.

- Uncertainty will be evaluated by expert opinion as necessary and expressed by the logic tree method. 


\section{Fragility Analysis}

- Structures and soil are evaluated by 3D response analysis such as FEM or other method. It calculates a lot of cases associated with all of the set of seismic waves given to each level of hazard and uncertainty.

- Response and uncertainty of large-scale structures and components are analyzed coupling with building as a part of building response analysis.

- Floor response spectrum and its uncertainty of other than large-scale structures and components are analyzed using the results of building response analysis. Response and its uncertainty, i.e. median and log-scale standard deviation, are calculated using individual specific frequency and attenuation factor of each component.

- Current analysing method of capacity and its uncertainty of component are improved using study insights described in Sect. 11.3.2.

\section{Accident Sequence Analysis}

- Improving SECOM2-DQFM code that can use the results of 3D probabilistic response analysis based on the DQFM method, it is possible to analyze the conditioned core damage probabilities for each input time history seismic wave.

- Core damage frequencies are calculated to integrate the products of frequencies of occurrence of all of time history seismic waves and conditioned core damage probabilities, respectively.

These features are represented by the formula which is proposed by Sewell et al. [6] as follows:

$$
\lambda[\Theta] \approx \sum_{\text {All } j} \Delta\left\{\lambda\left[x_{j}\right]\right\} \times \sum_{\text {All k }} P\left(T H_{k} \mid x_{j}\right) \times P\left[\Theta \mid T H_{k}, x_{j}\right]
$$

Here,

$\lambda[\Theta]$ : Annual rate of the event

$\Theta$ : The event that some generalized "state of interest" is realized

$$
\Delta\left\{\lambda\left[x_{j}\right]\right\}:\left\{\lambda\left[X \geq x_{j}\right]\right\}-\lambda\left[X \geq x_{j+1}\right]
$$

$X:$ A grand motion characterization

$x_{j}$ : A specific value of interest at a site of interest

$T H$ : Time history

As shown in Table 11.1, using 3D structure response analysis for fragility analysis, resolution, i.e. capability of scenario analysis, is enhanced significantly.

This framework requires large-scale calculations in the three fields such as composing a set of seismic waves of seismic hazard, large-scale probabilistic structure response analysis and quantification of system reliability model by 
Table 11.1 Expected enhancement of resolution of seismic PRA by introducing 1D probabilistic response analysis

\begin{tabular}{|c|c|c|c|}
\hline $\begin{array}{l}\text { Related task } \\
\text { of seismic } \\
\text { PRA }\end{array}$ & Issues & $\begin{array}{l}\text { Previous seismic PRA (AESJ } \\
\text { standard and so on) }\end{array}$ & $\begin{array}{l}\text { Improvements by } \\
\text { probabilistic } \\
\text { response analysis } \\
\text { of whole plant } \\
\text { using 3D FEM }\end{array}$ \\
\hline $\begin{array}{l}\text { Modelling of } \\
\text { initiating } \\
\text { events }\end{array}$ & $\begin{array}{l}\text { Needed to consider } \\
\text { multiple initiating } \\
\text { events such as } \\
\text { LOSP simulta- } \\
\text { neously. Current } \\
\text { method considers } \\
\text { the only single ini- } \\
\text { tiating event }\end{array}$ & $\begin{array}{l}\text { Simplified by hierarchical event- } \\
\text { tree method (Assuming capacity of } \\
\text { structures such as } \\
\text { Building }>\text { RPV > LOCA > Other } \\
\text { events }>\text { LOSP. Superior events } \\
\text { contain subordinate events. Con- } \\
\text { servative Evaluation) }\end{array}$ & $\begin{array}{l}\text { Possible to con- } \\
\text { sider multiple ini- } \\
\text { tiating events } \\
\text { simultaneously by } \\
\text { large-scale 3D } \\
\text { plant model }\end{array}$ \\
\hline $\begin{array}{l}\text { Evaluation of } \\
\text { failure proba- } \\
\text { bility of each } \\
\text { component }\end{array}$ & $\begin{array}{l}\text { Realistic analyses } \\
\text { are required sepa- } \\
\text { rately because } \\
\text { capacities of com- } \\
\text { ponents are evalu- } \\
\text { ated conservatively } \\
\text { in seismic design }\end{array}$ & $\begin{array}{l}\text { For large-scale passive compo- } \\
\text { nents, analyses in design stage or } \\
\text { detail analyses are referred. Active } \\
\text { mechanical and electrical compo- } \\
\text { nents are analyzed by verification } \\
\text { tests or vibration test results pro- } \\
\text { vided by the venders (Analysis } \\
\text { methods are chosen depending on } \\
\text { component types or availability of } \\
\text { data.) }\end{array}$ & $\begin{array}{l}\text { Basically, the } \\
\text { same as the previ- } \\
\text { ous method, but } \\
\text { detailed analyses } \\
\text { can consider the } \\
\text { diversity of spec- } \\
\text { trum characteris- } \\
\text { tics of seismic } \\
\text { motions and } \\
\text { decrease the } \\
\text { dependency on the } \\
\text { decisions by } \\
\text { analysts }\end{array}$ \\
\hline $\begin{array}{l}\text { Correlation } \\
\text { among com- } \\
\text { ponent } \\
\text { failures }\end{array}$ & $\begin{array}{l}\text { In analysis of } \\
\text { simultaneous fail- } \\
\text { ure probability of } \\
\text { multiplied systems, } \\
\text { simultaneous fail- } \\
\text { ures of the same } \\
\text { design compo- } \\
\text { nents. } \\
\text { i.e. consideration } \\
\text { of correlations, are } \\
\text { required }\end{array}$ & $\begin{array}{l}\text { Quantitative evaluation of degree } \\
\text { of correlation is difficult; simulta- } \\
\text { neous failures of the same design } \\
\text { components are assumed } \\
\text { conservatively }\end{array}$ & $\begin{array}{l}\text { It is possible to } \\
\text { rationalize the } \\
\text { analysis of acci- } \\
\text { dent scenarios and } \\
\text { the evaluation of } \\
\text { CDF by introduc- } \\
\text { ing detailed } \\
\text { response analysis } \\
\text { method of whole } \\
\text { structure that can } \\
\text { evaluate precisely }\end{array}$ \\
\hline $\begin{array}{l}\text { Analysis of } \\
\text { integrity of } \\
\mathrm{CV}\end{array}$ & $\begin{array}{l}\text { It is important to } \\
\text { analyze a location } \\
\text { of } \mathrm{CV} \text { failure for } \\
\text { accident } \\
\text { management }\end{array}$ & Detail analysis needed & $\begin{array}{l}\text { The same as the } \\
\text { left (It is possible } \\
\text { to consider the } \\
\text { diversity of spec- } \\
\text { trum characteris- } \\
\text { tics of seismic } \\
\text { motions) }\end{array}$ \\
\hline $\begin{array}{l}\text { Consideration } \\
\text { of ageing } \\
\text { effects }\end{array}$ & $\begin{array}{l}\text { It is desirable to } \\
\text { consider the impact } \\
\text { of the ageing of } \\
\text { component for } \\
\text { countermeasures of } \\
\text { ageing }\end{array}$ & Addressed as future work & $\begin{array}{l}\text { It could be easier } \\
\text { to evaluate the } \\
\text { risk increase by } \\
\text { reduction of } \\
\text { capacity of com- } \\
\text { ponents using 3D } \\
\text { FEM }\end{array}$ \\
\hline
\end{tabular}


Monte Carlo method. It could be possible to realize considering the recent enhancement of supercomputing and expansion of inexpensive providing supercomputing.

To develop the analyzing system based on the concept of framework, the following two options are proposed:

\subsubsection{Option A: Using High-Performance Computing Results Directly}

Detail processes of this option are as follows:

(1) Seismic Hazard Analysis Including Uncertainty Analysis

Seismic hazard is expressed by seismic motion that is described by a multiple set of seismic waves. However, to analyze uncertainty, each wave should include information of occurrence frequency, parameters of seismic source and propagation characteristics, uncertainty factor of those parameters such as occurrence probabilities, classification of aleatory and epistemic uncertainty.

(2) Soil-Structure Response Analysis Including Uncertainty Analysis

Probabilistic response of soil structure is analyzed by 3D analyzing method such as FEM or Sway-rocking model that can treat 3D characteristics to some extent. In these analyses, factors of uncertainty and probabilistic distributions are determined by experts. Moreover, to calculate rationally, random variables treated in the analysis are focused on the dominant parameters. The results should contain the detailed location in the buildings, calculation input parameters such as occurrence probabilities and classification of aleatory and epistemic uncertainty.

(3) Accident Sequence Analysis Including Uncertainty Analysis

Conditioned component failure probabilities and core damage probabilities are calculated using time history floor response obtained from soil-structure response analysis and component capacities for every time history data for seismic motions. In these analyses, uncertainties are analyzed as well using parameters for soil-structure response analysis.

(4) Uncertainty Analysis of CDF

$\mathrm{CDF}$ and its uncertainty are calculated using frequencies of time history data for seismic motions and the results of the above item (3).

Figure 11.2 shows the process described above, and this process is named as "the direct method".

In some cases, this option requires more than 10,000 times of calculations of large-scale 3D structure response analysis, because it is needed to set probabilistic distributions for soil-structure parameters that can be focused on about 20 parameters, associated with 300 or more of time histories of seismic motions. It is possible to treat such size of calculations by simplification of 3D detailed model to some 


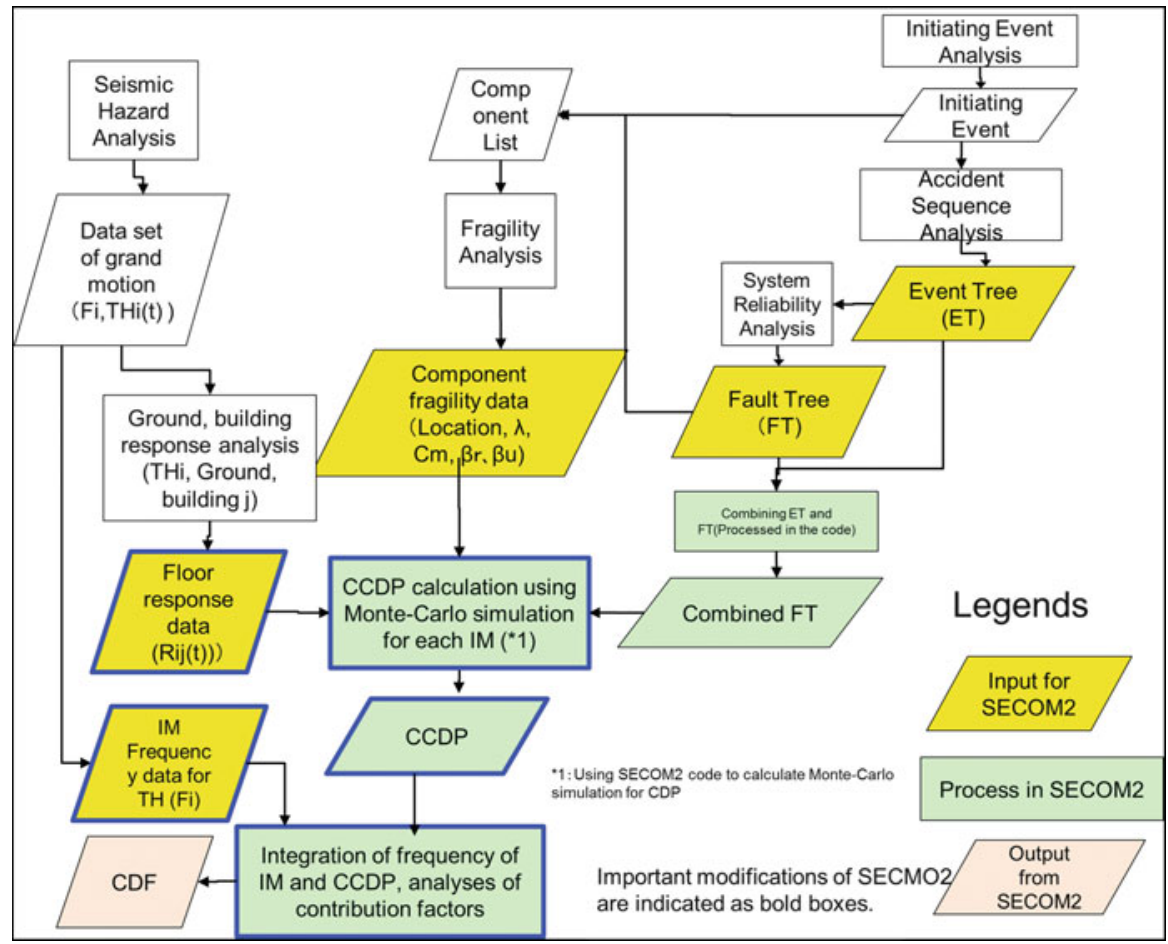

Fig. 11.2 Process of option A: Using high-performance computing results directly

extent and usage of supercomputers. However, since several sensitivity studies are required to analyze dominant factors, it is not practical.

\subsubsection{Option B: Using Intermediate Parameters such as Capacity Factors Derived from Building Response Analysis}

In seismic PRA process, so many trial and errors are needed to determine the analysis model, i.e. level of detail for system model and fragility. This means that the above "Option A" requires a lot of calculation times and is not practical. So combination of 3D analysis and response coefficient method is proposed as the intermediate method.

Preparing a number of calculations enough to simulate the probabilistic distributions of 3D analysis results at a certain degree of accuracy; then median, standard deviation and coefficient of correlation are determined to reproduce the results by response coefficient method using statistical analysis such as least-square method. Details of this method are as follows: 
(1) Seismic hazard analysis including uncertainty analysis:

This is the same as "Option A".

(2) Soil-structure response analysis including uncertainty analysis:

This is the same as "Option A" as well.

(3) Derivation of seismic hazard curve indexed by maximum acceleration in free rock surface and response coefficient:

Calculation of the basis ground motion, seismic hazard curve associated with maximum acceleration in free rock surface, median and standard deviation of response coefficient, and coefficient of correlation among components are needed to apply the framework of seismic PRA using conventional response coefficient method. Response coefficient should be set to express the characteristic of probabilistic distribution very well.

(4) Accident sequence analysis including uncertainty analysis:

Using information determined in the above (3), component failure probabilities associated with the maximum acceleration in free rock surface and conditioned core damage probabilities are evaluated. Along with these analyses, uncertainty is calculated using parameters for soil-structure response analysis as well.

(5) Uncertainty Analysis of CDF:

CDF and its uncertainty are calculated based on the seismic hazard curve indexed by the maximum acceleration in free rock surface and conditioned core damage probabilities as well as uncertainties calculated in the above (4).

Figure $11.3 \mathrm{a}, \mathrm{b}$ shows the optioned process related to the time history grand motions and floor responses described above, and these processes are named as "the intermediate method".

The most important point is that "response coefficient should be set to express the characteristic of probabilistic distribution very well by statistical analysis of the results of building 3D response analysis" described in item (3). This point is considered to be reasonable approximation if the three factors such as median, log-scale standard deviation and correlation are maintained properly in quantification process of CDF.

Based on this proposal, it could be expected that it is possible to model the more detailed 3D response characteristics of buildings and the more proper correlation that are the most important advantages of "Option A" by the practical calculation time.

However, this method is the intermediate and simplified method, and all of the advantages of $3 \mathrm{D}$ analysis could not be obtained. For example, the following issues need to be considered:

- Is it possible to introduce the index such as displacement, plastic deformation, other than acceleration in failure decision?

- Can it be suitably applied to the plastic region?

- Can the difference between the seismic source characteristics be reflected well in the calculation of the core damage frequency? 
a

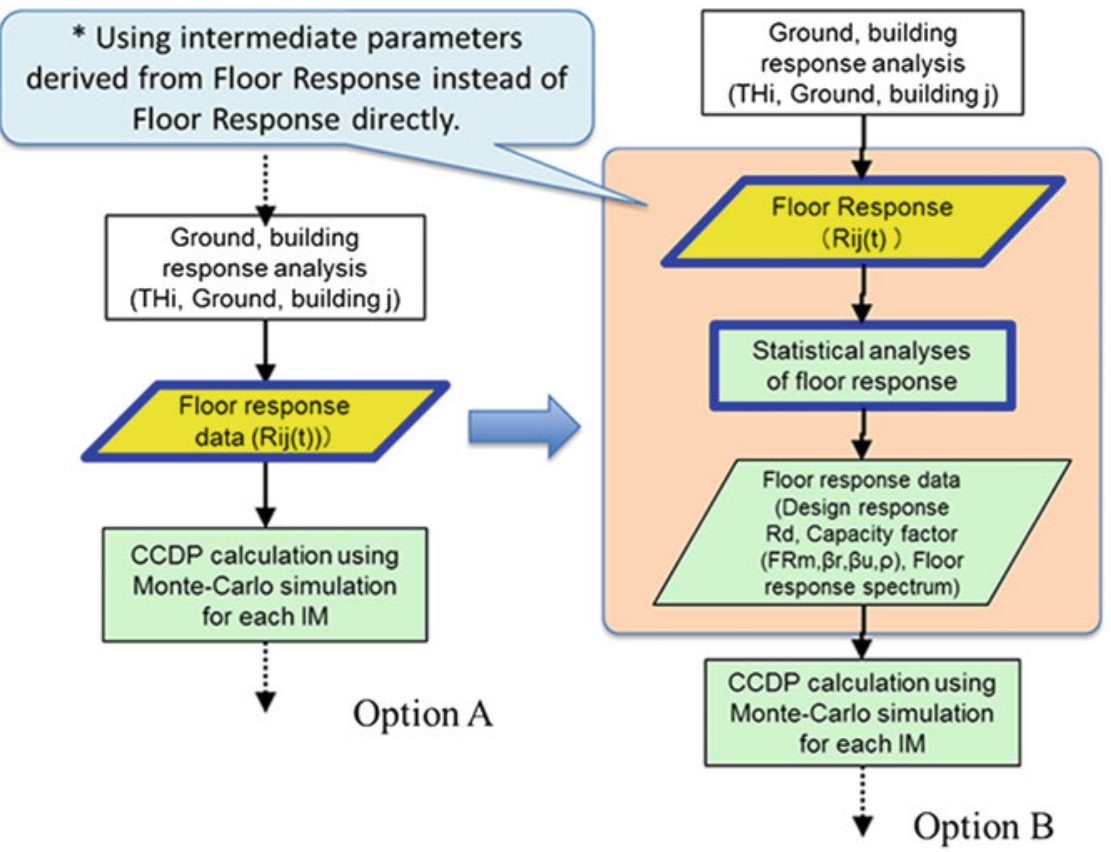

b

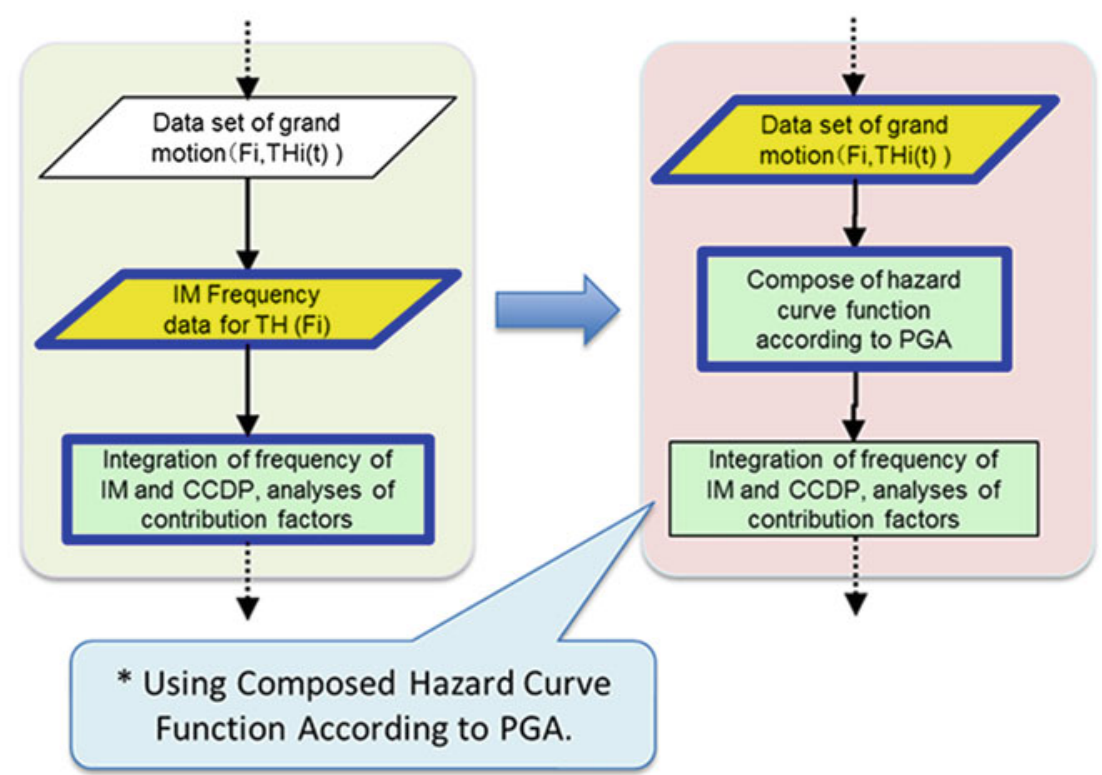

Fig. 11.3 (a) Comparison of options: Treatment of floor response (b) Comparison of options: Treatment of grand motion 
To resolve these issues, it can be considered that a set of response coefficient associated with maximum acceleration level in seismic center or site will be introduced and so on.

\subsection{Installation of Uncertainty Analysis Function Using Response Factor Method for SECOM2-DQFM}

\subsubsection{Improvement of SECOM2-DQFM CODE}

The function of uncertainty analysis for core damage frequency (CDF), accident sequence frequency and intermediate event frequency is installed in SECOM2DQFM. In detail, the followings are implemented:

- SECOM2-DQFM can be running on the large computing machine BX900 installed in JAEA.

- Improved to realize the large-scale grid computing.

- The uncertainty analysis function to calculate the uncertainty including aleatory uncertainty has been generally considered so far. The calculation time will be dramatically reduced by using hundreds of CPUs, even using proper set of random number for simulation.

- Improved to realize the uncertainty analysis of importance measurements such as FV importance.

- Improved to realize the uncertainty analysis, even considering the correlation among any events; that is one of the advantages of SECOM2-DQFM.

\subsubsection{Analysis Results}

Results of uncertainty analyses obtained by the improved and enhanced SECOM2DQFM using the BWR5 model plant input are shown in Fig. 11.4.

The point estimate values and the mean value of uncertainty analyses are consistent, and this means that improvement of SECOM2-DQFM by this study is reasonable. From the uncertainty analysis results, $5 \%$ lower value of $90 \%$ confidence interval could not be obtained because these are too low to plot on the chart. The error factor of total CDF, which is derived from $95 \%$ upper value of $90 \%$ confidence interval divided by median value, is 11.0 and is smaller than those of each accident sequence, which is more than 10,000 in some cases. It is presumed that $\mathrm{EF}$ of the larger contributing accident sequences tends to be smaller than the smaller contributers relatively because of their small EFs.

Moreover, the EFs of lower frequency accident sequences are relatively larger, and the EFs of higher frequency accident sequences are relatively smaller. This is because that smaller contributing accident sequences include the components with 


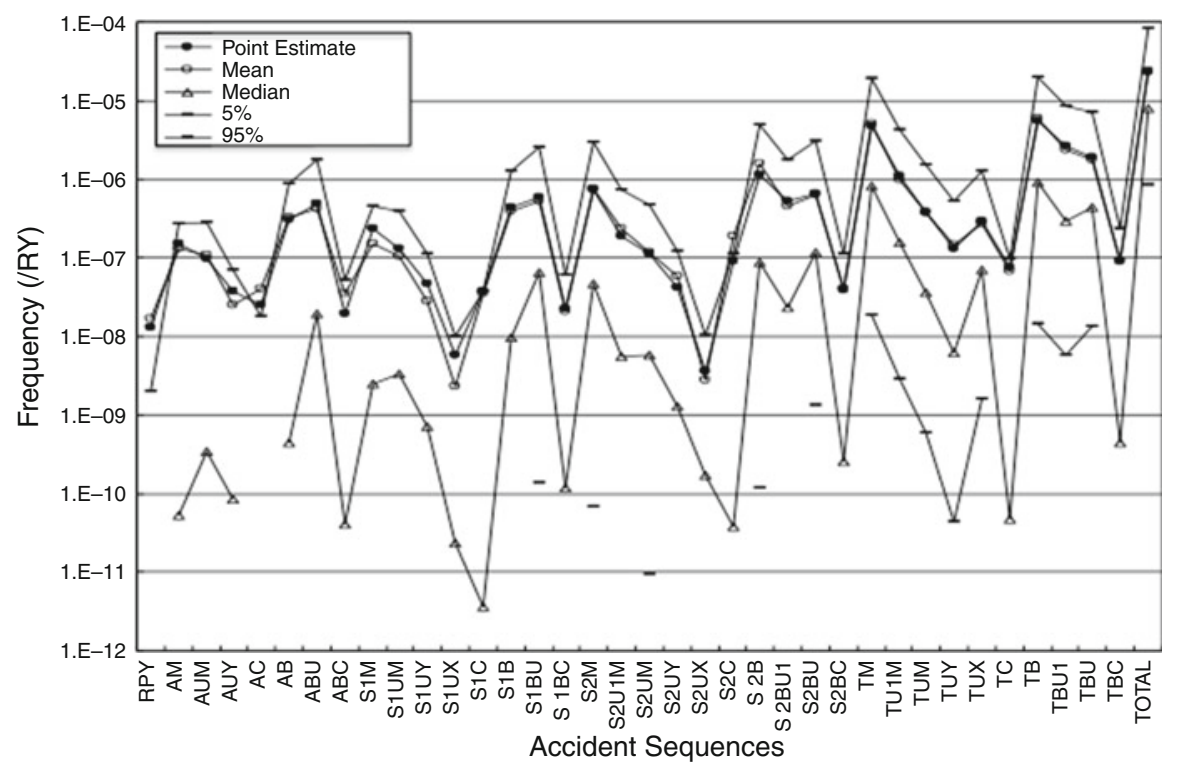

Fig. 11.4 Results uncertainty analyses for accident sequence frequencies

small fragility or redundancy. Especially, redundant components have complex relations of uncertainty, and these are cumulated in the calculation, and this is why the EFs of these accident sequences are so large.

\subsection{Conclusions}

A new framework is proposed to improve the resolution capability of seismic PRA. Improvement of computer code SECOM2 for quantification of FTs by Monte Carlo simulation is done. Based on these, capability of parallel processing was implemented to allow uncertainty analysis in a reasonable time for seismic PRA with the current model framework (response coefficient framework).

This study proposed the mathematic framework to treat the uncertainty properly related to the evaluation of core damage frequency induced by earthquake, the method to evaluate the fragility utilizing expert knowledge, the probabilistic model to cope with the aleatory uncertainty, as well as the development of analyzing code including these considerations for the improvement of the reliability of the method and enhancement of utilization of the products of seismic PRA.

Acknowledgements This study is performed as a part of a 3-year project "Reliability Enhancement of Seismic Risk Assessment of Nuclear Power Plants as Risk Management Fundamentals", which was started in 2012 and is funded by the Ministry of Education, Culture, Sports, Science and Technology (MEXT) of Japan. 
Open Access This chapter is distributed under the terms of the Creative Commons Attribution Noncommercial License, which permits any noncommercial use, distribution, and reproduction in any medium, provided the original author(s) and source are credited.

\section{References}

1. Kennedy RP et al (1980) Probabilistic seismic safety study of an existing nuclear power plant. Nucl Eng Des 59:315-338

2. Smith PD et al (1981) Seismic safety Margins Research Program, NUREG/CR-2015

3. Nishida A et al (2013) Characteristics of simulated ground motions consistent with seismic hazard, SMiRT-22

4. Muramatsu K et al (2008) Effect of correlations of component failures and cross-connections of EDGs on seismically induced core damages of a multi-unit site. J Power Energy Syst JSME 2 (1):122-133

5. Kawaguchi K et al (2012) Efficiency of analytical methodologies in uncertainty analysis of seismic core damage frequency. J Power Energy Syst JSME 6(3):378-393

6. Robert T, Sewell et al (2009) Recent findings and developments in probabilistic seismic hazards analysis (PSHA) methodologies and applications, NEA/CSNI/R 